\title{
Characteristics of winter wheat genotypes with different degree of resistance to Fusarium (Fusarium ssp.) in terms of resistance to powdery mildew (Blumeria graminis)
}

\section{Charakterystyka genotypów pszenicy ozimej o zróżnicowanym stopniu odporności na Fusarium (Fusarium ssp.) pod kątem odporności na mączniaka prawdziwego (Blumeria graminis)}

Danuta Kurasiak-Popowska, Jerzy Nawracała, Zuzanna Sawinska, Dorota Weigt, Agnieszka Tomkowiak

\section{Summary}

The field experiment was carried out in 2010-2012 at the Experimental Station of the Department of Genetics and Plant Breeding, Poznań University of Life Sciences. The study was designed to evaluate the degree of infection by powdery mildew (Blumeria graminis) on 25 winter wheat genotypes characterized by high and varied resistance to Fusarium. On average, the lowest infection by powdery mildew, amounting to 4 degrees in a 9-degree scale was observed on the two registered Polish varieties (Ostroga and Natula), 4 genotypes from Austria, 2 from Hungary and one from Sweden, while the highest infection in the case of two Polish varieties Muszelka and Sukces. Low FHB (Fusarium head blight) index was characterized by certain genotypes considered as resistant and three Polish varieties: Fregata, Sukces and Ostroga. Wheat genotypes poorly infected by Fusarium with the average or low susceptibility to powdery mildew were: Ertus, Fregata, 20816, Poros, Ostroga and Kubanskaya 122.

Key words: winter wheat; powdery mildew; Fusarium

\section{Streszczenie}

Doświadczenie polowe przeprowadzono w latach 2010-2012 w Rolniczym Gospodarstwie Doświadczalnym Dłoń, na polu Stacji Doświadczalnej Katedry Genetyki i Hodowli Roślin Uniwersytetu Przyrodniczego w Poznaniu. Badania miały na celu ocenę stopnia porażenia przez mączniaka prawdziwego zbóż i traw (Blumeria graminis) 25 genotypów pszenicy ozimej charakteryzującej się wysoką, jak i zróżnicowaną odpornością na grzyby rodzaju Fusarium sp. Średnio najniższe porażenie przez mączniaka prawdziwego, wynoszące do 4 stopni w skali 9-stopniowej, zaobserwowano w 2 zarejestrowanych odmianach polskich (Ostroga i Natula), w 4 genotypach z Austrii, 2 z Węgier i 1 ze Szwecji, natomiast najwyższe - w przypadku dwóch polskich odmian Muszelka i Sukces. Niskim indeksem fuzariozy kłosa cechowały się niektóre genotypy uznawane jako odporne oraz trzy polskie odmiany: Fregata, Sukces i Ostroga. Genotypami pszenicy ozimej słabo porażanymi przez fuzariozę kłosa, o jednocześnie średniej bądź niskiej podatności na mączniaka prawdziwego były: Ertus, Fregata, 20816, Poros, Ostroga i Kubanskaya 122.

Słowa kluczowe: pszenica ozima; mączniak prawdziwy; Fusarium 


\section{Wstęp / Introduction}

Jedną z najważniejszych i stwarzających największe zagrożenie chorób pszenicy jest fuzarioza kłosa. Jej szkodliwość polega nie tylko na bezpośrednim zmniejszeniu plonu, ale również na obniżeniu jego jakości przez wytwarzanie różnego rodzaju mykotoksyn. W przypadku pszenicy, gatunki rodzaju Fusarium powodują skażenie ziarna toksynami takimi, jak: deoxyniwaleron (DON), zearalenon (ZEN), niwanelon (NIV), moniliformina (MON), które mogą powodować, że zebrane ziarno będzie nieprzydatne do spożycia przez ludzi i zwierzęta. Najnowsze badania wskazują, że zanieczyszczenie ziarna pszenicy tymi mykotoksynami w Polsce jest bardzo duże. Twarużek i wsp. (2013) stwierdzili obecność DON i ZEN we wszystkich badanych próbach ziarna pszenicy z całego kraju. Zabiegi ochrony roślin ograniczają występowanie chorób wywoływanych przez grzyby, w tym Fusarium, ale nie zapobiegają stratom plonu i pogorszeniu jakości ziarna (Weber 2007). Biorąc również pod uwagę ochronę środowiska przyrodniczego, najlepszym rozwiązaniem jest uprawa odmian odpornych lub odmian o mniejszej podatności na porażenie przez grzyby. Problem hodowli odmian odpornych na Fusarium wynika z tego, że odporność roślin na Fusarium jest odpornością poziomą i ma charakter kompleksowy. Według dotychczasowych badań nie stwierdzono całkowitej odporności na fuzariozę kłosów wśród odmian pszenicy zwyczajnej. Najlepszą odporność wykazują genotypy ze środkowej i wschodniej Azji, głównie formy jare, w tym chińska odmiana pszenicy jarej Sumai 3 (Snijders 1990; Bai i Shaner 1994; Bürstmayr i wsp. 2009). Drugą grupę stanowią odmiany pochodzące z Ameryki Południowej, do których zalicza się odmiany: Frontana, Encruzilhada i Estanzuela Young (Snijders 1990; Bai i wsp. 2003; Góral 2005). Możliwość wykorzystania ich w programach hodowlanych jest ograniczona, gdyż charakteryzują się one podatnością na inne choroby, nadmierną wysokością i niskim plonowaniem (Góral 2005; Brown-Guedira i wsp. 2008).

Celem badań była ocena stopnia porażenia przez mączniaka prawdziwego zbóż i traw (Blumeria graminis) genotypów pszenicy ozimej charakteryzującej się wysoką, jak i zróżnicowaną odpornością na grzyby rodzaju Fusarium sp.

\section{Materiały i metody / Materials and methods}

Materiał badawczy stanowiło 25 odmian i linii pszenicy ozimej ze zgromadzonej w Katedrze Genetyki i Hodowli Roślin Uniwersytetu Przyrodniczego w Poznaniu kolekcji genotypów pszenicy ozimej (tab. 1). Większość badanych genotypów uznawanych jest (na podstawie danych literaturowych i danych z kolekcji USA) za genotypy w małym stopniu porażane przez gatunki grzybów rodzaju Fusarium. Wśród nich reprezentowane są trzy zasadnicze źródła odporności: z chińskiej jarej pszenicy Sumai 3, z brazylijskiej jarej odmiany Frontana i z pszenic ozimych ze wschodniej Europy. Genotypy te otrzymano z kolekcji pszenicy National Smalle Grain Collection znajdującej się w Agriculture Research Station w Aberdeen, należącej do National Plant Germplasm System w USA oraz od dr. T. Górala (IHAR, Radzików) i zostały one wstępnie ocenione jako odporne, a pochodziły $\mathrm{z}$ dziewięciu państw europejskich takich, jak: Austria, Czechy, Francja, Holandia, Niemcy, Rosja, Rumunia, Szwecja, Węgry, które w hodowli pszenicy ozimej są wykorzystywane jako źródła odporności na Fusarium. Do doświadczenia wybrano również 8 odmian pszenicy ozimej wyhodowanych w Polsce o zróżnicowanej odporności na Fusarium - uznawane za bardzo podatne na infekcję oraz genotypy o średniej podatności na fuzariozę kłosów.

Doświadczenia polowe założone zostały w Rolniczym Gospodarstwie Doświadczalnym Dłoń, na polu Stacji Doświadczalnej Katedry Genetyki i Hodowli Roślin Uniwersytetu Przyrodniczego w Poznaniu, w latach 2009/2010, 2010/2011 oraz 2011/2012. Wybrane 25 genotypów wysiewano na poletkach o powierzchni $1 \mathrm{~m}^{2}$ $(1 \mathrm{~m} \times 1 \mathrm{~m})$, w układzie bloków losowanych w trzech powtórzeniach.

W doświadczeniu zastosowano dwie kombinacje:

1. Brak ochrony chemicznej, naturalne porażenie chorobami.

2. Brak ochrony chemicznej, sztuczna inokulacja grzybami rodzaju Fusarium.

Do produkcji inokulum zastosowano kilka izolatów grzybów rodzaju Fusarium porażających pszenicę, reprezentujących różne gatunki, charakteryzujące się wysoką patogenicznością: $F$. graminearum i $F$. culmorum - po

Tabela 1. Genotypy pszenicy ozimej badane w doświadczeniu

Table 1. Winter wheat genotypes tested in the experiment

\begin{tabular}{l|l|l}
\hline $\begin{array}{c}\text { Genotyp } \\
\text { Genotype }\end{array}$ & \multicolumn{1}{c|}{ Rodowód - Pedigree } & \multicolumn{1}{c}{ Kraj - Country } \\
\hline \multicolumn{1}{c|}{1} & \multicolumn{1}{|c}{2} & \multicolumn{1}{c}{3} \\
\hline 20816 & Capo $\times$ Sumai 3 & Austria - Austria \\
\hline 20817 & Capo $\times$ Sumai 3 & Austria - Austria \\
\hline 20818 & Capo $\times$ Sumai 3 & Austria - Austria \\
\hline 20828 & Capo $\times$ Sumai 3 & Austria - Austria \\
\hline A40-22-1-2 & Capo $\times$ SVP 72017 & Austria - Austria \\
\hline Praag 8 & odmiana lokalna - local variety & Czechy - Czech Republic \\
\hline $81-$ F3-79 & Ringo Star $\times$ Adam & Francja - France \\
\hline Bizel & {$[($ Blé Bohémien $\times$ Blé Seigle $) \times$ Oro $] \times$ Variant de Hauters } & Francja - France \\
\hline SVP C8718-5 & SVP 72017-17-5-10 $\times\{$ Petit Quinquin $\times[$ Vogel $1222 \times($ H101 $\times$ Comanche $)]\}$ & Holandia - The Netherlands \\
\hline
\end{tabular}




\begin{tabular}{|c|c|c|}
\hline 1 & 2 & 3 \\
\hline Türkis & Tambor $\times$ Hadm 91639-89 & Niemcy - Germany \\
\hline Poros & Stamm-3151-45 × (Hadmerslebener-IV) Trumpf & Niemcy - Germany \\
\hline Kubanskaya 122 & Stavropolka-328 $(2 \times) \times($ Kanred $\times$ Fulcaster $)$ & Rosja-Russia \\
\hline F $201 \mathrm{R}$ & F156I5-2112 × F2076W12-11 & Rumunia-Romania \\
\hline Ertus & Eroica $\times$ Virtus & Szwecja - Sweden \\
\hline UNG 226 & $($ Sumai $3 \times 81.60) \times$ Kincsö & Węgry - Hungary \\
\hline UNG 136.6.1.1 & $($ Sagvari $\times$ Nobeokabozu $) \times($ Minimano $\times$ Sumai 3$)$ & Węgry - Hungary \\
\hline UNG 136.16.4.7 & $($ Sagvari $\times$ Nobeokabozu $) \times($ Minimano $\times$ Sumai 3$)$ & Węgry - Hungary \\
\hline Fregata & Kobra $\times$ Astron & Polska - Poland \\
\hline Kampana & nieznany - unknown & Polska - Poland \\
\hline Kohelia & nieznany - unknown & Polska - Poland \\
\hline Muszelka & Kris $\times$ Rubens & Polska - Poland \\
\hline Natula & $($ Flair $\times$ Elena $) \times$ Astron & Polska - Poland \\
\hline Ostroga & nieznany - unknown & Polska - Poland \\
\hline Sakwa & nieznany - unknown & Polska - Poland \\
\hline Sukces & Jubilatka $\times$ SMH 2182 & Polska - Poland \\
\hline
\end{tabular}

3 izolaty z każdego gatunku. Inokulację przeprowadzono przez opryskiwanie roślin zawiesiną zarodników w ilośc $1 \times 10^{6}$ zarodników w $1 \mathrm{ml}$ zawiesiny. Opryskiwanie przeprowadzono dwukrotnie w odstępie tygodniowym w okresie kwitnienia roślin pszenicy.

Nasilenie fuzariozy kłosów oceniano na poletkach inokulowanych od momentu ukazania się pierwszych objawów choroby. Po trzech tygodniach od drugiej inokulacji oceniono porażenie przez fuzariozę kłosów. Ocena porażenia fuzariozą i mączniakiem prawdziwym zbóż i traw wykonana została w oparciu o klucz graficzny do oznaczania chorób opracowany przez EPPO (European and Mediterranean Plant Protection Organization). Index fuzariozy obliczono według wzoru: Index fuzariozy kłosa $(\mathrm{IFK})=$ (procent porażenia kłosa $\times$ procent kłosów porażonych na poletku)/100. Ocenę stopnia porażenia genotypów przez mączniaka przeprowadzono na poletkach w kombinacji z naturalnymi warunkami porażenia przez choroby w skali od 1 - najmniej porażone do 9 - całkowicie porażone.

Dla analizowanych cech przeprowadzono jednoczynnikową analizę wariancji. Najmniejszą istotną różnicę (NIR) obliczono przy pomocy testu Tukeya, na poziomie $\alpha=0,05$.

\section{Wyniki i dyskusja / Results and discussion}

Warunki pogodowe w latach badań miały znaczący wpływ na występowanie chorób (tab. 2). Głównym czynnikiem sprzyjającym występowaniu i rozwojowi grzyba $B$. graminis są częste opady deszczu, których rezultatem jest wysoka wilgotność powietrza, wynosząca powyżej 80\% (Kochman i Węgorek 1997; Walczak i wsp. 2010). Duża ilość opadów w maju 2010 roku spowodowała istotny wzrost nasilenia porażenia pszenicy przez mączniaka prawdziwego. W latach zbioru 2011 i 2012 suma opadów w maju była znacznie niższa od średniej z wielolecia, a porażenie przez mączniaka było zdecydowanie niższe. W latach badań średnie wartości porażenia badanych genotypów przez mącznika prawdziwego były zróżnicowane i w sezonie 2009/2010 istotnie wyższe statystycznie niż w roku zbioru 2012 (tab. 3).

Znajomość reakcji odmian na fuzariozę kłosa i inne choroby jest konieczna ze względu na możliwość wykorzystania genotypów w programach krzyżówkowych. Analizowany zestaw odmian obejmował zarówno genotypy uznawane jako źródła odporności, jak i uprawiane polskie odmiany pszenicy ozimej. W tabeli 3. zamieszczono średni dla 3 lat indeks fuzariozy kłosa. Niskim indeksem fuzariozy kłosa odznaczały się trzy odmiany polskie - Fregata, Sukces i Ostroga. Zastosowanie inokulacji wywołało silne porażenie, skutkujące indeksem fuzariozy przekraczającym $20 \%$ w przypadku 5 polskich odmian - Muszelka, Natula, Sakwa, Kampana i Kohelia.

Większość genotypów sprowadzonych z banku genów jako odporne na Fusarium potwierdziła swoją odporność w warunkach Polski. Zarówno w pracy Górala (2005), jak i w przeprowadzonych badaniach genotypy: Praag 8, Kubanskaya 122 oraz Ertus należały do genotypów słabo porażanych przez fuzariozę kłosa. Trudniej natomiast porównywać same wartości indeksu fuzariozy kłosa, gdyż niewątpliwie wpływ warunków klimatycznych, glebowych oraz sam proces inokulacji modyfikował zakres uzyskanych wyników. W analizowanym doświadczeniu indeks fuzariozy odmiany Praag 8 wynosił 5,4\%, natomiast w badaniach Snijdersa (1990) wynosił on w przypadku tej odmiany zaledwie $1,7 \%$, a w pracy Górala (2005) - 9,5\% .

Interesujące wydają się oceny porażenia przez fuzariozę dla linii, w rodowodach których znajduje się azjatycka odporna odmiana jara Sumai 3. Spośród nich tylko genotyp 20816 cechował się wysoką odpornością, natomiast genotypy węgierskie i pozostałe austriackie odznaczały się średnim bądź wysokim indeksem fuzariozy. Niska odporność tych genotypów na Fusarium odbiega od wyników uzyskanych przez Bürstmayra i wsp. (2008), w których te 
same genotypy odznaczały się wysoką odpornością. Wskazywać to może na istotny efekt interakcji genotypowośrodowiskowej (Masterhazy i wsp. 1999), jak również na brak odporności poziomej. Oetler i Wahle (2001) badając reakcję 100 genotypów pszenżyta na inokulacje przez F. culmorum stwierdzili, że interakcja genotypowo-środowiskowa stanowiła $30 \%$ wariancji genotypowej.

Tabela 2. Średnie miesięczne temperatury i sumy opadów w sezonach 2009/2010, 2010/2011, 2011/2012 oraz w wieloleciu (stacja meteorologiczna w Dłoni)

Table 2. Average monthly temperatures and rainfall sums in 2009/2010, 2010/2011, 2011/2012 (weather station in Dłoń)

\begin{tabular}{|c|c|c|c|c|c|c|c|c|}
\hline \multirow[t]{2}{*}{$\begin{array}{l}\text { Miesiąc } \\
\text { Month }\end{array}$} & \multicolumn{4}{|c|}{$\begin{array}{l}\text { Średnia temperatura powietrza } \\
\text { Average air temperature }\left[{ }^{\circ} \mathrm{C}\right]\end{array}$} & \multicolumn{4}{|c|}{$\begin{array}{c}\text { Suma opadów } \\
\text { Rainfall sum [mm] }\end{array}$} \\
\hline & $2009 / 2010$ & $2010 / 2011$ & $2011 / 2012$ & 1956-2009 & $2009 / 2010$ & $2010 / 2011$ & $2011 / 2012$ & 1956-2009 \\
\hline Kwiecień - April & 9,1 & 11,9 & 10,4 & 8,2 & 45,0 & 17,0 & 23,0 & 32,0 \\
\hline Maj-May & 11,4 & 15,4 & 17,8 & 13,5 & 125,0 & 37,5 & 26,9 & 55,3 \\
\hline Czerwiec-June & 18,8 & 19,0 & 18,3 & 16,8 & 44,0 & 33,5 & 133,9 & 66,2 \\
\hline Lipiec - July & 22,8 & 18,6 & 22,1 & 18,4 & 64,0 & 169 & 95,4 & 82,1 \\
\hline
\end{tabular}

Tabela 3. Porażenie 25 genotypów pszenicy ozimej przez mączniaka prawdziwego oraz średni indeks fuzariozy kłosa z trzech lat obserwacji (Dłoń)

Table 3. Infection of 25 genotypes of winter wheat by powdery mildew and average FHB (Fusarium head blight) index, three years observation (Dłoń)

\begin{tabular}{|c|c|c|c|c|c|}
\hline \multirow{2}{*}{$\begin{array}{l}\text { Genotyp } \\
\text { Genotype }\end{array}$} & \multirow{2}{*}{$\begin{array}{c}\text { Indeks fuzariozy kłosa } \\
\text { FHB index } \\
{[\%]}\end{array}$} & \multicolumn{4}{|c|}{$\begin{array}{l}\text { Stopień porażenia przez mączniaka prawdziwego (B. graminis) } \\
\text { The degree of infection by powdery mildew }(\text { B. graminis })\end{array}$} \\
\hline & & $2009 / 2010$ & $2010 / 2011$ & $2011 / 2012$ & średnia - mean \\
\hline Ertus & 0,4 & 2,5 & 5 & 2 & 3,2 \\
\hline Fregata & 2,1 & 8 & 4 & 2 & 4,7 \\
\hline 20816 & 3,5 & 3,5 & 6 & 2 & 3,8 \\
\hline Poros & 4,4 & 5,5 & 5 & 2 & 4,2 \\
\hline Praag 8 & 5,4 & 9 & 4 & 1 & 4,7 \\
\hline Sukces & 7,6 & 7,5 & 9 & 6 & 7,5 \\
\hline Ostroga & 8,3 & 6,2 & 2 & 2 & 3,4 \\
\hline Kubanskaya & 8,4 & 9 & 1 & 2 & 4,0 \\
\hline F $201 \mathrm{R}$ & 9,4 & 9 & 9 & 2 & 6,7 \\
\hline A40-22-1-2 & 12,9 & 2 & 6 & 2 & 3,3 \\
\hline Bizel & 13,2 & 9 & 6 & 2 & 5,7 \\
\hline 20828 & 13,8 & 8,5 & 1 & 2 & 3,8 \\
\hline $81 \mathrm{~F} 379$ & 16,2 & 9 & 2 & 2 & 4,3 \\
\hline UNG 226 & 18,4 & 6,7 & 1 & 2 & 3,3 \\
\hline UNG 136.6.1.1 & 20,4 & 8,2 & 3 & 2 & 4,4 \\
\hline Kohelia & 20,9 & 3,5 & 9 & 4 & 5,5 \\
\hline 20818 & 22,7 & 6,5 & 5 & 2 & 4,5 \\
\hline Turkis & 24,7 & 4,2 & 9 & 6,6 & 6,6 \\
\hline SVP C 8718-5 & 25,5 & 7,5 & 6 & 2 & 5,2 \\
\hline 20817 & 27 & 9 & 1 & 2 & 4,0 \\
\hline Kampana & 27,2 & 4,5 & 2 & 8 & 4,8 \\
\hline Sakwa & 27,5 & 2,5 & 9 & 7 & 6,2 \\
\hline UNG 136.16.4.7 & 28,8 & 8,5 & 1 & 2 & 3,8 \\
\hline Natula & 31,2 & 3,5 & 5 & 3 & 3,8 \\
\hline Muszelka & 41,3 & 4,5 & 9 & 6,7 & 6,8 \\
\hline Średnia & 16,8 & $6,3 \mathrm{~b}$ & $4,8 \mathrm{ab}$ & $3,05 \mathrm{a}$ & 4,7 \\
\hline
\end{tabular}

Średnie wartości z tą samą literą nie różnią się istotnie - Mean values with the same letter do not differ significant 
Zarówno odmiana Sumai 3, jak i jej pochodne oraz brazylijska odmiana Frontana zostały szeroko wprowadzone do programów hodowlanych jako źródła odporności (Badea i wsp. 2008). Poleganie wyłącznie na jednym lub dwóch źródłach odporności może jednak powodować znaczny spadek efektywności wprowadzonych w takich programach genów (McCartney i wsp. 2004). Aby skutecznie i długoterminowo wykorzystywać zarówno istniejące, jak i nowe źródła odporności na Fusarium niezbędne jest ciągłe analizowanie i poszukiwanie materiału hodowlanego. Fuzarioza kłosa poza zmniejszeniem plonu powoduje zanieczyszczenie ziarna szkodliwymi dla zdrowia mikotoksynami. Uzyskane wyniki zarówno w tej pracy, jak i w pracy Górala (2005) wskazują na potrzebę wprowadzenia nowych źródeł odporności pszenic na fuzariozę kłosa równolegle $\mathrm{z}$ genami odporności na inne patogeniczne grzyby. Dodatkowo znaczny udział zbóż i kukurydzy w strukturze zasiewów w Polsce wskazuje, że problem porażania pszenicy przez choroby powinien być dogłębnie przeanalizowany w naszym kraju (Weber 2007).

Średnie dla trzech lat porażenie roślin przez mączniaka prawdziwego wynosiło 4,72 w skali 9-stopniowej (tab. 3). Zakres reakcji genotypów wynosił od 3,17 dla szwedzkiej odmiany Ertus do 6,75 dla odmiany Muszelka. Średnio najniższe porażenie przez mączniaka prawdziwego, wynoszące do 4 stopni w skali 9-stopniowej zaobserwowano w 2 zarejestrowanych odmianach polskich (Ostroga i Natula), w 4 genotypach z Austrii, 2 z Węgier i 1 ze Szwecji. Najwyższe średnie porażenie przez mączniaka prawdziwego odnotowano w przypadku dwóch polskich odmian - Muszelka i Sukces.

Genotypami pszenicy ozimej słabo porażanymi przez fuzariozę kłosa, o jednocześnie średniej bądź niskiej podatności na mączniaka prawdziwego były: Ertus, Fregata, 20816, Poros, Ostroga i Kubanskaya. Genotypy te mogą zostać wykorzystane do poprawienia odporności polskich odmian pszenicy. Przy wyborze genotypu odpornego należy zwrócić uwagę na odporność na inne choroby grzybowe oraz cechy użytkowe, aby uniknąc wprowadzenia cech niekorzystnych. Odmiana Sukces, która była w małym stopniu porażana przez Fusarium, była jednocześnie najmniej odporna na mączniaka prawdziwego zbóż i traw (B. graminis).

\section{Wnioski / Conclusions}

1. Genotypami pszenicy ozimej słabo porażanymi przez fuzariozę kłosa, o jednocześnie średniej bądź niskiej podatności na mączniaka prawdziwego były: Ertus, Fregata, 20816, Poros, Ostroga i Kubanskaya.

2. Warunki pogodowe w latach badań wpływały na poziom nasilenia mączniaka prawdziwego.

\section{Literatura / References}

Badea A., Eudes F., Graf R.J., Laroche A., Gaudet D.A., Sadasivaiah R.S. 2008. Phenotypic and marker-assisted evaluation of spring and winter wheat germplasm for resistance to fusarium head blight. Euphytica 164: 803-819.

Bai G.H., Shaner G. 1994. Scab of wheat. Prospects for control. Plant Dis. 78: 760-766.

Bai G.H., Guo P.G., Kolb F.L. 2003. Genetic relationships among head blight resistant cultivars of wheat assessed on the basis of molecular markers. Crop Sci. 43: 498-507.

Brown-Guedira G., Griffey C.A., Kolb F.L., McKendry A.L., Murphy P.J., Van Sanford D. 2008. Breeding FHB-resistant soft winter wheat: progress and prospects. Cereal Res. Comm. 36, Suppl. B: 31-35.

Bürstmayr H., Ban T., Anderson J.A. 2009. QTL mapping and marker-assisted selection for Fusarium head blight resistance in wheat: a review. Plant Breeding 128: 1-26.

Bürstmayr H., Lemmens M., Schmolke M., Zimmermann G., Hartl L., Mascher F., Trottet M., Gosman N.E., Nicholson P. 2008. Multienvironment evaluation of level and stability of FHB resistance among parental lines and selected offspring derived from several European winter wheat mapping populations. Plant Breeding 127: 325-332.

Góral T. 2005. Źródła odporności pszenicy na fuzariozę kłosa powodowaną przez Fusarium culmorum (W.G. Smith) Sacc. Biul. IHAR 235: $115-131$.

Kochman J., Węgorek W. 1997. Choroby infekcyjne. s. 445-447. W: „Ochrona roślin” (J. Kochman, W. Węgorek, red.). Wyd. V, Plantpress, Kraków, 701 ss.

Masterhazy A., Bartok T., Mirocha C.G., Komoroczy R. 1999. Nature of wheat resistance to Fusarium head blight and the role of deoxynivalenol for breeding. Plant Breeding 118: 97-110.

McCartney C.A., Somers D.J., Fedak G., Cao W. 2004. Haplotype diversity at Fusarium blight resistance QTLs in wheat. Theor Appl. Genet. 109: 261-271.

Oettler G., Wahle G. 2001. Genotypic and environmental variation of resistance of head blight in triticale inoculated with Fusarium culmorum. Plant Breeding 120: 297-300.

Snijders C.H.A. 1990. Genetic variation for resistance to Fusarium head blight in bread wheat. Euphytica 50: 171-179.

Walczak F., Tratwal A., Krasiński T. 2010. Kierunki rozwoju prognozowania i sygnalizacji agrofagów w ochronie roślin rolniczych. [Directions of the development of pest forecasting and warning systems in plant protection]. Prog. Plant. Prot./Post. Ochr. Roślin 50 (1): 81-86.

Twarużek M., Grajewska-Wanat N., Błajet-Kosicka A., Grajewski J. 2013. Występowanie grzybów rodzaju Fusarium oraz głównych mikotoksyn w ziarnie zbóż w latach 2011-2012. [Occurrence of Fusarium and major mycotoxins in cereal grains harvested in 2011-2012]. Prog. Plant Prot./Post. Ochr. Roślin 53 (4): 801-806.

Weber R. 2007. Zagrożenie i sposoby ograniczania chorób fuzaryjnych pszenicy. Post. Nauk Rol. 2: 19-31. 